\title{
Surgery and Emotion: The Era Before Anaesthesia
}

\author{
Michael Brown
}

\section{INTRODUCTION}

In July 1824 an anonymous correspondent wrote to the recently established reform-minded medical journal, The Lancet, to express his concern about the manner in which operations were being conducted at the London hospitals of Guy's and St Thomas'. 'When the fiat of an hospital surgeon has determined a patient to an operation', he began, 'the space of time from that moment to the moment of his conveyance to the theatre must be a time of increasing anxiety and distress'. This period, he acknowledged, could vary from a few hours to a few days and was often requested by the patient themselves, but whatever was the case, it was the duty of the surgeon to 'make this anxious interval as short as possible'. Yet if the period of waiting was fraught, then it was as nothing compared to what took place when the patient was finally brought into the operating theatre:

Feverishly heated, and frequently very much exhausted by his previous sufferings, every additional moment, at this dreadful crisis, becomes to him an hour, and every additional moment that he continues under the torture of the different instruments, diminishes the chance of success and ... increases the danger of his life.

With this in mind, the correspondent was pained to recall a recent operation he had witnessed for the removal of a stone from the bladder of a young boy.

\author{
M. Brown $(\bowtie)$ \\ University of Roehampton, London, UK \\ e-mail: Michael.Brown@roehampton.ac.uk
}

(C) The Author(s) 2018

T. Schlich (ed.), The Palgrave Handbook of the History of Surgery, https://doi.org/10.1057/978-1-349-95260-1_16 
Despite having already inspected the child, or so the correspondent assumed, the surgeon chose this 'dreadful moment' to re-examine him, inserting a metal sound through his urethra and into his bladder. 'Unfortunately he could not feel the stone, till after trying in all directions, and putting the boy in excruciating pain for several minutes, he, at last, satisfied himself and gave the instrument into the hand of another surgeon, for further testimony'. This surgeon likewise had great difficulty in locating the calculus and so handed the sound to a third colleague. According to the correspondent:

These examinations occupied a full twenty minutes, during the whole of which time the boy continued screaming and was nearly exhausted before the operation commenced ... Now a great part of this painful process might be, or ought to be avoided. It is woeful to the patient, it is disgraceful to the surgeon ...

This letter was only one of a number of accounts of botched and bungled operations to appear in The Lancet in the first three decades of its existence and it paints a vivid picture of the potential terrors of pre-anaesthetic surgery. It suggests that the successful prosecution of surgery in this period was dependent upon a carefully calibrated performance designed not simply to reduce the pain and suffering of the patient but also to manage their psychological correlates, fear and anxiety. What is also remarkable about it is the emotive register of the language employed. The correspondent not only expresses deep regret at the agonies of the boy but, by imagining himself into the patient's position, appears to affect a profoundly intersubjective emotional engagement; 'the operation ... was tedious', he states, 'and the effect of the whole upon my mind was distressing-What must it have been to the young sufferer?'l

This chapter explores the place of emotion in the practice and representation of surgery in the first half of the nineteenth century, with a particular focus on the UK.

The historical study of the emotions is a burgeoning field, but to date it has made relatively little impact on the historiography of surgery. This is somewhat peculiar because surgery represents one of the most profoundly challenging emotional, psychological and physiological experiences that, as a patient, it is possible to undergo. Becoming an object of surgical expertise and subject to direct physical intervention can produce intense feelings of fear and anxiety, even in an age of anaesthesia and keyhole surgery. Likewise, the feelings of joy and relief at a successful operation can be as subjectively powerful today as they were for Samuel Pepys when he had his bladder stone removed in $1658 .^{2}$ Moreover, there is every reason to believe that emotion, or the supposed mitigation of it, has been, and continues to be, central to the construction of surgical professional identity. In 2013, for example, an Australian study found that surgeons tended to adopt a 'heroic' mode which focused on 'fixing' problems and established an emotional distance between themselves and their patients. ${ }^{3}$ By contrast, the personal testimonies of 
surgeons, such as that of the neurosurgeon Henry Marsh, often talk of the influence of a range of emotions from pity and regret to elation and pride. ${ }^{4}$

These issues are therefore as relevant to the post-anaesthetic period as they are to that which preceded the introduction of ether and chloroform in the 1840s. Nevertheless, there is something about the early nineteenth century that makes it particularly suitable for a study of the emotional cultures of surgery. In relative terms, of course, surgical operations in this period were nowhere near as ambitious as those of the later 1800s, let alone those of today. In the absence, not only of effective pain relief to manage shock, but also of adequate measures to stem blood loss or the ability to control postoperative infection, surgeons were generally unwilling or unable to intrude into the body's three main cavities of abdomen, thorax and cranium. ${ }^{5}$ Even so, the mere thought of having a leg amputated without any kind of anaesthetic, let alone submitting to a protracted lithotomy, such as the boy referred to above had to endure, is liable to make the modern reader flinch in sympathy. Moreover, the historical record abounds with accounts of surgical procedures that give full expression to the reality of suffering. Of these perhaps the most famous is Frances Burney's mastectomy, performed in 1811 during her time in France. Burney was attended by an unusually large team of practitioners, including two of the leading surgeons of the day, Dominique Jean Larrey, surgeon-in-chief to the Imperial army, and Antoine Dubois, consultant surgeon to Napoleon himself. She was deeply apprehensive about the procedure, confiding to her sister Esther that the 'dread and repugnance, from a thousand reasons besides the pain almost shook all my faculties'. ${ }^{6}$ She had every reason to be fearful; Dubois had told her that she must expect to suffer very severely, and so she did:

Yet-when the dreadful steel was plunged into the breast-cutting through veins, arteries-flesh-nerves-I needed no injunctions not to restrain my cries. I began a scream that lasted unremittingly during the whole time of the incision-and I almost marvel that it rings not in my Ears still! so excruciating was the agony. ${ }^{7}$

Burney fainted twice during the operation but she was lucky; she survived and went on to live for another twenty-nine years. Her testimony provides a profound insight into the pain and mental anguish experienced by surgical patients in this period. But what is less well known about this account is the light it sheds upon the emotional dispositions of the operators themselves. It is revealing that men of deep experience such as Larrey and Dubois, men who were used to witnessing the sufferings of the battlefield, were profoundly moved by Burney's situation. Larrey reportedly 'had tears in his Eyes' on contemplating the procedure, while Dubois found himself unable to speak when Burney asked whether 'he could feel for an operation that, to You, must seem so trivial'. ${ }^{8}$ In fact, so powerful were the surgeons' emotions that, during the operation itself, Burney spoke only to assure them how much she 


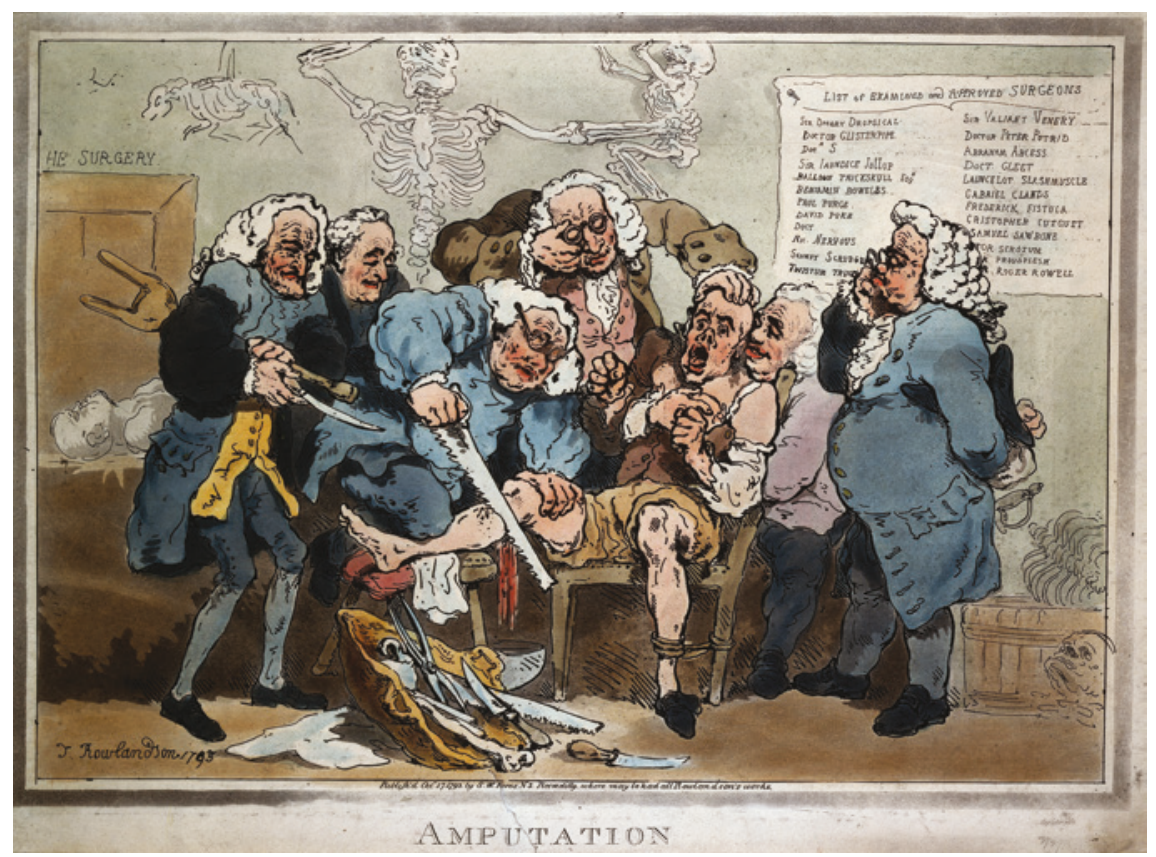

Fig. 1 Thomas Rowlandson, ‘Amputation' (1793), Wellcome Library, London

pitied them, 'for indeed I was sensible to the feeling concern with which they all saw what I endured'.?

This image of the emotionally attuned and expressive surgeon contrasts markedly with much of the received wisdom on surgical identity in the premodern era. Surgeons are, for the most part, thought of as coolly dispassionate, and those of the past as brusque or even cruel. Satirical representations, such as Thomas Rowlandson's 'Amputation' of 1793 (Fig. 1) sustain this impression, as do the statements of subsequent surgical generations who often had an active interest in presenting the past as grossly inferior to the present. ${ }^{10}$ So too, for that matter, does the historical scholarship. One of the few works to explore the relationship between surgery and emotion in the Early Modern period is Lynda Payne's With Words and Knives: Learning Medical Dispassion in Early Modern England (2007), although her book is more of an intellectual history of surgery and anatomy than a history of the emotions per se. The very first sentence of her book makes clear the assumption which underpins its central premise. 'In practice', she states, 'physicians, and especially surgeons, have always had to learn some type of detachment (or dispassion to use the Early Modern term) in order to cope with the more revolting aspects of their art'. ${ }^{11}$ This presumption of a kind of emotional ahistorcity notwithstanding, Payne presents a convincing argument that the seventeenth and eighteenth centuries saw the elaboration of a culture of surgical dispassion rooted 
in anatomical observation, Epicurean restraint, religious stoicism and bodily self-discipline. Her study culminates with the example of the great eighteenthcentury surgeon-anatomist brothers William and John Hunter. The former famously told his students that anatomy not only 'informs the head' and 'gives dexterity to the hand' but also 'familiarizes the heart with a sort of necessary inhumanity, the use of cutting instruments upon our fellow creatures'. ${ }^{12}$ Occasionally this state of dispassion, which Payne takes as indicative of a much wider mind-set, could shade over into a caricature of the surgeon as unfeeling brute. In William Blake's Island in the Moon (1784), for example, the surgical character Jack Tearguts (a thinly veiled satire of John Hunter) is described thus: 'he does not mind their crying - tho they cry ever so [-] he'll Swear at them \& keep them down with his fist \& tell [them] that he'll scrape their bones if they don't lay still $\&$ be quiet'. ${ }^{13}$

This model of the surgeon as rough, physical and relatively insensitive to pain and suffering has also been applied to the nineteenth century. In his essay 'Medical Minds, Surgical Bodies: Corporeality and the Doctors' (1998), for example, Chris Lawrence acknowledges the rising status of surgery during the century but maintains that surgeons hardly escaped their established associations with the butcher's trade. Quite the contrary, in fact; he suggests that surgeons built upon these associations to shape identities that were in keeping with contemporary social values: 'it was the sorts of qualities embodied in the butcher, a capacity for physical endurance, solidity, and honesty-that were highly prized in the Victorian cult of manliness'. ${ }^{14}$

Between Payne's eighteenth-century stoics and Lawrence's rough-andready men of action, however, we have something of a lacuna. To employ a somewhat arbitrary institutional benchmark, the years between the creation of the Royal College of Surgeons of London in 1800 and the granting of a second Royal Charter to extend the College's authority to the whole of England in 1843 were pivotal to the social and professional establishment of English (and, more broadly, UK) surgery and yet they remain relatively understudied. One of the few books to cover this period is Peter Stanley's For Fear of Pain: British Surgery, 1790-1850 (2003). As well as providing a broad overview of surgical practice in this period Stanley also points the way to a more embodied and emotionally nuanced history. Thus, while acknowledging that 'clinical accounts rarely describe or explicitly reflect surgeons' reactions to or feelings about their work', Stanley does not simply assume that stoicism or dispassion were the order of the day. ${ }^{15}$ Rather, he cites numerous examples of operators expressing fear, anxiety, dread, pity and sympathy, particularly where vulnerable patients such as children were concerned. ${ }^{16} \mathrm{He}$ also provides a number of cases where patients expressed their feelings about the prospect of an operation or reflected on the outcome of one. ${ }^{17}$

Similar insights have also been provided by the literature on pain and anaesthesia. In 1985 Martin S. Pernick challenged the widespread popular perception that anaesthesia brought about a sudden, near miraculous, end to hundreds of years of agonising surgery, demonstrating instead how the 
volatility and unpredictability of early anaesthetics, as well as the continued resonance of pain as an indicator of sensibility, meant that many practitioners were extremely cautious about how, and with whom, they employed them. ${ }^{18}$ As he also demonstrates, understandings of pain were shaped by a complex 'social politics' of class, race and gender, something which has also been borne out by Stephanie Snow in her study of anaesthesia in the UK. ${ }^{19}$ More recently still, in her broad account of the history of pain, Joanna Bourke acknowledges the traditional image of pre-modern medicine as cruel or uncaring before suggesting that sympathy might actually have played a more important social and rhetorical function than has generally been recognised. ${ }^{20}$

Bourke's work offers suggestive avenues for further study and is part of a growing literature on the history of the emotions. To date, much of this literature has been theoretical and abstract as scholars continue to debate terms and concepts; there has been relatively little application of these methodologies to specific historical case studies. Historians of emotion have sought to chart a difficult path between an essentialist model of emotions grounded in psychology, which maintains that emotional responses are neurologically hardwired, and an anthropological reading which would suggest that the experience of emotion is culturally and historically relative. Historians have likewise grappled with the thorny issue of whether we can truly access and interpret the phenomenology of emotions, that is their felt experience, or whether we must restrict ourselves to the expression of emotions, that is emotional discourse and the discourse of emotions. ${ }^{21}$ Two of the earliest pioneers of the history of the emotions, Carol and Peter Stearns, were inclined towards the latter view, coining the term 'emotionology' to distinguish the prevailing emotional standards of the day (which are historically recoverable) from the lived experience of emotion (which is not). ${ }^{22}$ Another notable contribution to the terminology of the field comes from Barbara Rosenwein, who introduced the concept of 'emotional communities' as a way of thinking about how emotions are shared, sustained and policed within specific social groups. ${ }^{23}$ Rosenwein is also helpfully critical of what she calls the 'hydraulic model' of emotions, a linear historical concept promoted by Norbert Elias' Civilising Process (trans 1969) which assumes that, over time, societies learn to 'control' themselves more effectively. ${ }^{24}$ Of equal value to historians is the work of William Reddy. Reddy's signal achievement is the concept of 'emotives', which reconciles the psychological/anthropological divide by suggesting that emotions share certain essential qualities but that their meanings and expression (particularly verbal 'utterances') are historically relative and, more than this, serve to shape experience and social relations. He is also responsible for the concept of 'emotional regimes', similar in many ways to Rosenwein's 'emotional communities', albeit perhaps more restrictive and oppressive, requiring 'emotional navigation' and occasionally productive of 'emotional suffering'. ${ }^{25}$

Whatever one thinks of the utility of Reddy's concept of emotional regimes there can be no doubt that his work has done much to emphasise the politics of emotion, particularly in relation to his given case study of the 
French Revolution. Such an approach is potentially fruitful for enhancing our understanding of the history of surgery. Bourke's argument about the neglected place of sympathy in medicine is well-observed but, as is perhaps inevitable with such a synoptic account, she does not provide much by way of explanation or analysis as to the roots of this culture of sympathy, how it developed or, without wanting to be too instrumentalist, what political functions it served. In this chapter I therefore want to offer some tentative suggestions in this general direction. Specifically, I want to suggest that, shaped by the cultures of Enlightenment sensibility, early nineteenth-century surgeons, who were increasingly turning their backs on the heroic surgery of the preceding era, reframed the notion of what it was to be a good surgeon, combining, if not necessarily displacing, the physical model of the 'capital operator' with the moral ideal of the man of feeling who could not simply amputate a limb in under a minute, but who, in the most profound sense, was capable of sympathising with his patients and who sought at all times to minimise their pain and suffering. Needless to say, this transformation in identities and practices had a complex set of origins, but it was a profoundly political process. The later decades of the eighteenth and early decades of the nineteenth century were a period in which British surgery came to fruition as a self-consciously scientific discipline. In 1800, the Company of Surgeons had become the Royal College of Surgeons and surgical practitioners were looking to the legacy of men like John Hunter in order to present themselves as informed, considered and capable performers. ${ }^{26}$ Indeed, so successful was this process of refashioning that, by the middle of the nineteenth century, surgery had arguably overtaken medicine in terms of reputation and prestige. At one level then, this emphasis upon physical restraint and emotional sophistication allowed surgeons to challenge the conventional stereotype of the illmannered and ignorant sawbones with a more culturally resonant ideal. At another level, however, it also played a more antagonistic political function. As with the rest of the British medical world, early nineteenth-century surgery was split by an emergent movement for reform in which politically radical and professionally marginal surgeon-apothecaries sought to challenge the hegemonic authority of the metropolitan hospital and corporate elites. As we shall see, within this context, the pain and suffering of patients could, when presented as the corollary of incompetence and corruption, form a powerful critique of a nepotistic and monopolistic surgical oligarchy.

\section{Surgical Performance: Art and Artifice}

Surgery had long been regarded as an art that required considerable manual dexterity. Unfortunately, contemporary sources are rarely as clear or as detailed as they might be on the embodied skills deemed necessary for the practice of operative surgery, as these skills were generally inculcated through other, more praxial, forms of education. Nevertheless, nineteenth-century textbooks would often offer advice as to the correct way of handling the knife 
and of making basic incisions as well as on procedures such as suturing. It was generally accepted that practice with the knife was essential but that practice alone could never make perfect. As one correspondent to The Lancet put it, the public, thinking surgery a

mere mechanical operation ... conclude that frequent practice, with a proper knowledge of anatomy, must make them perfect performers but this is not the case; daily practice upon a musical instrument will never make some people good players ... nor will [surgical practice] make a good operator of the man who has neither the eye ... nor the dexterity of finger which are the necessary prerequisites for such a performer. ${ }^{27}$

For medical students, practice was usually undertaken upon cadavers so that the operator might at least familiarise himself with the anatomy of the body and the physical resistance provided by flesh and bone. However, all agreed that, no matter how many bodies one cut up, it was never enough to prepare one for the experience of a living, breathing, writhing patient and, as opportunities to perform actual operations, especially capital procedures such as amputations or lithotomies, were relatively limited, it was possible for a student to qualify as a surgeon without ever having done so. He might have participated in numerous such operations as an assistant or 'dresser', but it is unlikely that he would have taken charge of such a procedure himself.

In her ethnographic study of contemporary American surgical education, Rachel Prentice states that 'Surgeons must teach both skills and meaning'. Most of the surgeons she worked with spoke of technical skill as constituting a mere $20 \%$ of surgical education, 'falling lower in importance than difficult-to-quantify qualities of wisdom, judgement and experience'. ${ }^{28}$ Such was also case for the nineteenth century. Indeed, confronted by the prospect of a sentient patient in extraordinary pain, such considerations were arguably even more important. Surgical lecturers often found that, if the skills of the hand could at least be taught, then those of the mind and nerves were not so easily imparted. Addressing his students in 1823, the foremost surgical operator of the day, Sir Astley Cooper, claimed that 'the quality which is considered of the highest order in surgical operations, is self-possession; the head must always direct the hand, otherwise the operator is unfit to discover an effectual remedy for unforeseen accidents that may occur in his practice'. ${ }^{29}$ Over thirty years later, Frederic Skey's advice was similar: 'He should possess great firmness of purpose ... to be acquired only by previous thought and preparation, and a self-possession which no accident, however unlooked for, can disturb or alienate'. ${ }^{30}$ In theory, then, self-confidence and self-possession were the natural consequence of thorough study and training. But for an inexperienced practitioner, the prospect of major surgery could be a deeply intimidating one, not least when even senior practitioners admitted to anxiety in advance of a procedure or showed themselves to be less than assured during one.

The stakes were especially high for the fact that early nineteenth-century surgery could be a highly public spectacle. Certainly a large number of 
operations, probably more than we generally recognise, were undertaken in private residences, but at most hospitals, especially the large London teaching hospitals and, as the century wore on, in many smaller provincial hospitals too, operations were undertaken in front of sometimes large audiences of students and practitioners. In such an arena the surgeon's every gesture could be subject to intense scrutiny. Generally, the exquisite repertoire of surgical performance demanded focused precision. Surgeons were actively discouraged from talking to their assistants unless strictly necessary. Any dressers or others present around the operating table should be briefed in advance and their actions in theatre directed with nothing more conspicuous than a discreet glance or motion of the hand. Surgeons were similarly discouraged from addressing the audience or offering instruction. Needless to say, the absolute worst thing one could do was panic. Many did, however, especially when confronted by every surgeon's worst nightmare, haemorrhage. ${ }^{31}$ The discharge of great quantities of blood from a patient was liable to test the nerves of even the most capable practitioner. This was especially true if the bleeding was of an indeterminate origin, the surgeon desperately struggling to find the source of the haemorrhage as the patient turned pale and their pulse began to weaken. In the early 1820s, therefore, Cooper's students were regaled with a cautionary tale in which an inexperienced young dresser persuaded a member of staff at Guy's Hospital to allow him to amputate his leg so that he might gain the necessary experience. Rather than the Hospital's theatre, however, the operation took place surreptitiously in the student's own residence and, on initiating his incision, he was met with 'a great discharge of blood'. "Screw the tourniquet tighter", he urged his assistant but, in so doing, the screw broke and, losing 'all presence of mind ... he jumped about the room, then ran to the sufferer and endeavoured to stop the effusion of blood by compressing the wound with his hand; his sleeve became filled with blood and [the] poor [patient] would have died ... had not a pupil ... had the presence of mind to apply the key of the door to the femoral artery'. ${ }^{32}$

However, while physical performance and operative dexterity remained important, the first half of the nineteenth century saw an increasing scepticism directed toward the idea that it constituted the sole, or even the primary component of a surgeon's identity. In articles, lectures and textbooks, surgeons repeatedly cautioned against being seduced by the knife. In part this scepticism entailed a distrust of performance itself, a sense that bravura display might conceal as much as it revealed. This is what James Wardrop had to say to his students at the Aldersgate Street medical school in the early 1830s:

Some of you may have heard of instances where surgeons, in other respects deservedly eminent, forgetting the duties of civilized life, have attempted a kind of theatrical effect in performing operations, for no other purpose than to give bystanders a false impression of their dexterity, coolness, and presence of mind ... that affectation of dexterity, or doing operations quickly, is but a pitiful ambition in those who use it ... but you will invariably observe that none except 
those who are deficient in moral courage ... find it necessary to resort to such conduct; and that a man who feels himself equal to the task he undertakes proceeds deliberately and calmly, steadily bearing in mind the grand object-relief to the patient. ${ }^{33}$

More generally, this scepticism derived from a set of broader intellectual trends that combined to bring about the decline of the heroic age of operative surgery and usher in a new era of relative procedural conservatism. ${ }^{34}$ One of these trends, and one that received much notice from contemporary surgical lecturers apt to conceive of the history of their speciality in teleological terms, was the advances in surgical science that had characterised the latter decades of the eighteenth century. Numerous lecturers claimed that surgeons of an earlier generation were likely to cut precisely because they were ignorant of the body's true forms and functions. However, because of the pioneering work of John Hunter, a man hardly noted for his operative skill, surgeons were now more knowledgeable and, hence, more cautious, or so they argued. Similarly, as in certain quarters of the medical world where the Parisian clinical revolution of the turn of the century had engendered a certain therapeutic nihilism, many early nineteenth-century surgeons seemed equally loath to intervene and inclined to trust to the curative powers of nature.

\section{EMOTION AND INTERSUBJECTIVITY}

Just as importantly, however, these early nineteenth-century surgical texts are also suggestive of a deeper cultural and emotional transformation. In the lectures of men like Wardrop, neophyte surgeons were encouraged almost to resent the knife and to place selfless compassion for the patient above any consideration of personal interest. 'It is difficult perhaps to be explained', he claimed, 'but it is not on that account the less true that some individuals seem absolutely to have a predilection for performing surgical operations: whereas we should naturally suppose that nothing would be more repulsive to our nature than the infliction of pain on our fellow beings'. Quoting John Bell, a man to whom we shall return, he maintained that 'Those qualities which relate to operations and other public exhibitions of skill are of a very doubtful kind, while the duties of humanity and diligence are far more to be prized'. ${ }^{35}$

The ideal surgeon of the early nineteenth century was, therefore, to be a man of feeling, a man who, because of what Frederic Skey acknowledged to be the 'grand' yet 'terrible' power they possessed, should be capable of the most profound emotional transportation: 'A man is disqualified [from the duties of surgery]', Skey explained to his readers, 'who cannot divest his mind of the sense of all personal advantage accruing to him from the performance of an operation, who cannot in imagination place himself in the position of the patient, and reflect on the case in all its bearings and calculate the result as though his own personal health were directly involved'. ${ }^{36}$ 
The essential tension of surgical decision making, to cut or not to cut, was summed up thus by Astley Cooper earlier in the century:

Sorry indeed should I be, to sport with the life of a fellow-creature who might repose a confidence either in my surgical knowledge or in my humanity; and I should be equally disposed to consider myself culpable, if I did not make every possible effort to save a person whose death was rendered inevitable, if a disease were suffered to continue which it was possible for surgery to relieve ... In the performance of our duty one feeling should direct us; the case we should consider as our own and we should ask ourselves, whether, placed under similar circumstances, we should submit to the pain and danger we are about to inflict. ${ }^{37}$

When one is alert to its presence, it is remarkable quite how prominent this mode of emotional intersubjectivity was within the cultures of early nineteenth-century operative surgery. It does not form whole chapters of surgical textbooks, though occasionally lecturers such as Wardrop or authors like Skey might make such moral considerations the subject of their preliminary remarks. In general, however, it is widely diffused among case reports, letters and articles, a sentence here or a phrase there which, when taken together as a discursive collage, is suggestive of something much more pervasive and important.

There are a number of reasons why the early nineteenth century provided a particularly fruitful ground for the development of a discourse of surgical compassion. In addition to the factors to which I have already alluded, namely an increasingly conservative approach to surgical intervention, the early nineteenth century also saw the continued development of a culture of sentiment, sympathy and sensibility whose origins lay in the Enlightenment work of John Locke, David Hume and Adam Smith and through which the capacity to feel the pain of others and to moderate our actions accordingly became perhaps the highest expression of human nature. ${ }^{38}$ In addition, while the development of anaesthesia in the 1840s and 1850s tended to diminish the patient's presence, making them a relatively passive object of surgical technique the early nineteenth-century patient exerted a very vocal and physical agency which needed to be both managed and harnessed. Within this context, a certain emotional sensibility was essential to gauge the state of mind of the patient in advance of an operation. In his lectures, for example, James Wardrop advised against operating on persons of nervous temperament unless strictly necessary. This was especially important, he suggested, because the mind could exercise such a profound influence over the body that any amount of 'moral depression' could cause a patient to sink and die even after relatively minor surgery. In general, he suggested, it was important to ascertain whether the patient's fear derived 'from the dread of the temporary pain of the operation' or whether they were convinced that the operation itself would kill them. The former, he maintained, could be managed, while the latter was invariably a self-fulfilling prophecy. ${ }^{39}$ 
Such considerations were so vital to the successful outcome of an operation that they served to structure the most precise of details. Like Sir Astley Cooper and numerous other contemporary surgeons, Wardrop advised that any instruments necessary for an operation should be covered over until the surgeon was ready to proceed. Likewise, there was 'nothing the surgeon should so much avoid, as by his dress, to impress [the patient] with an idea that the operation will be attended by much bloodshed'. ${ }^{40}$ A dark set of trousers and a shirt were infinitely preferable to a full-length apron.

In its highest form, this emotional and psychological intersubjectivity did not simply require a surgeon to be compassionate or considerate: it demanded the exercise of a profound moral authority over one's patients. As Benjamin Brodie told his audience in Windmill Street in the 1820s:

You must ever recollect, Gentlemen, that those beings on whom you are destined to practise are endowed with a percipient, thinking mind, and that that mind will become in the highest degree irritable from a variety of causes such as long confinement, sleepless nights, painful days; now it will prove greatly to your advantage and success if you should be capable of regulating your patient morally and well as physically. But it may be asked here, Who can regulate the minds of others, if they are incapable of commanding their own? and I therefore address to you the expressive words of the poet ... 'Man, know thyself' ... I do not hesitate to say that he who can look with indifference on the agonies of a fellow creature is not the person to practise surgery. ${ }^{41}$

What Brodie is advancing here is the idea that the moral authority of the surgeon had to derive from an emotional, intellectual and psychological self-mastery. In order to command his patient, the surgeon first needed to understand himself, including both his capacities and his limitations. Indeed, operators in this period were frequently cautioned not to overreach themselves in the quest for reputation but to operate with an informed and modest restraint. More importantly perhaps, he is suggesting that the ideal surgeon was a kind of emotional savant, a man so finely attuned to his own affective self that he was receptive to even the most subtle or complex emotional signs emitted by his patients and was able to exert a calming and reassuring influence through mere confidence and composure.

Brodie's comments, and those of other surgeons, suggest that pre-anaesthetic surgery constituted a collaborative endeavour in which both patient and practitioner had to play an active and sustained part. In some cases the two forged an effective (and indeed affective) partnership in the most trying of circumstances. In January 1824, for example, Astley Cooper was called upon to perform one of the most challenging of all procedures, namely the amputation of the leg at the hip joint, on a forty-year-old man who was suffering serious complications from a previous amputation at the knee. The operation lasted twenty minutes and was beset with complications but nonetheless, 'the patient bore the operation with extraordinary fortitude and after 
all was finished he said to Sir Astley, "that was the hardest day's work he had ever gone through", to which Sir Astley replied "that it was almost the hardest he ever had"'.42 In other cases, however, the patient's physical and mental distress could further complicate the procedure, even to the extent of offering unconscious resistance to the will of the surgeon. Thus another amputation at the hip joint, this one undertaken at the Middlesex Hospital, was met with

some difficulty, in consequence of the extreme irritability of the stump ... and partly from the obstreperous conduct of the patient ... That fortitude which induced him to solicit an operation, and which supported him when placed on the table, forsook him in an instant, on the first touch of the knife. His motions, which were almost convulsive at this period, seriously endangered the fingers of the operator. ${ }^{43}$

\section{The Politics of Pain and the Reform of Emotions}

There is a danger, of course, of advancing an overly essentialist or ontological reading of surgical emotion. After all, these expressions of feeling and sentiment were often rhetorical, contained in lectures or textbooks that sought to present an idealised image of surgical practice. This does not mean that we should restrict ourselves to an 'emotionological' reading of surgical history, however. It is entirely possible that surgeons of this period developed this complex emotional and psychological repertoire and there is no doubt that the cultures of sensibility and sentimentality had a profound effect on the felt experience of emotion. Nonetheless, what it does suggest is that we should consider the politics of the emotions in relation to surgery and to consider what role sympathy and sensibility played in the shaping of surgical culture and identity.

The origins of this particular transformation in surgical identities are complex and have yet to be fully elucidated. Nevertheless, one suggestive case study concerns John Bell and the cultures of medicine and surgery in turn-of-the-century Edinburgh. John Bell (1763-1820) is perhaps best known as the older brother of Charles Bell (1774-1842), the celebrated Scottish anatomist and physiologist. ${ }^{44}$ However, John was also a noted surgeon, anatomist and author in his own right and in 1800 he became embroiled in a heated and protracted dispute with James Gregory (1753-1821), Professor of the Practice of Physic at Edinburgh University. James Gregory, who was born into Scottish medical aristocracy as the son of the celebrated John Gregory (1724-1823), had inherited positions at the University, first from this father and subsequently from William Cullen (1710-1790). It was perhaps the security provided by such privilege that gave Gregory the confidence to indulge in feuds with his colleagues, something which he did with apparent regularity. In 1800 he published a pamphlet entitled Memorial to the Managers of the Royal Infirmary in which he attacked the system by which the medical and surgical posts at the hospital were filled by a monthly rotation of mostly junior members of the college of physicians and 
college of surgeons. Gregory's intervention effectively put an end to this practice and established a system of permanent appointments. In so doing, however, he earned the ire of Bell who, as the self-appointed spokesperson for the junior members of the Royal College of Surgeons, was not only upset about losing a personal privilege but who maintained that the whole structure of practical education for surgeons had been critically undermined.

So far, so parochial; but what is particularly interesting about the voluminous body of deeply ill-tempered screed that this dispute produced is the manner in which Bell outlined a strikingly novel defence of surgical character. Bell was particularly offended at Gregory's characterisation of junior surgeons as lacking experience and ability. 'He mocks at all dignity' he claimed, 'at all semblance of science, at all professional skill, faith, honesty, or honour; and we and our cruelties are his constant theme'. ${ }^{45}$ Rejecting such egregious accusations, he alleged that:

To become skilled [as a surgeon], a man must live among the sick: he must have lively feelings, and a sympathizing nature; his mind and senses must be deeply impressed with the character of every kind of suffering; he must have that inward sympathy with the distresses of his fellow-creature[s], which fills the mind with sincere and affectionate interest ... In our profession, young men should have instilled into their minds that sympathy with the sufferings of their patient, and that keen spirit of investigation should be roused in them, which refines every sense, and quickens the intellect. ${ }^{46}$

Such emotional sincerity, Bell alleged, was in contrast to Gregory himself, whose role as a physician insulated him from the affective intensity of the operating theatre:

Has his mind been thus keenly touched, almost disordered, at the miseries of his fellow creatures? No, no! his strong sensibilities we hold but lightly: He never passed a sleepless night, reflecting what was to be done on the morrow; never witnessed the severities of the surgeon; never strained hard his breath, nor involuntarily clenched his hands at the sight of another's agony; nor blanched with fear, nor felt the palpitations of anxiety, in the midst of an eventful operation? ${ }^{47}$

What Bell is suggesting here was that surgeons were not merely avoiding unnecessary cruelty, they were in actual fact far superior to physicians in their capacity for emotional engagement. However, in making this claim, Bell was doing more than simply attaching surgery to a culturally resonant ideal, he was actively locating this particular dispute within a wider discourse of sensibility and its discontents.

By the latter decades of the eighteenth century, the culture of sentiment, which had formed a vital part of Enlightenment gentility, was being called into question by some who saw it as little more than a fashionable artifice, exposing the foppery and effeminacy of polite society. ${ }^{48}$ Perhaps the most celebrated example of this is the Scottish author Henry Mackenzie's 1771 novel 
The Man of Feeling which, a mere few years after its publication, was roundly mocked for its excessive lacrimation. ${ }^{49}$ However, rather than devaluing sensibility per se, such debates suggested a distinction between artificial performance on the one hand and honest emotion on the other. Bell alluded on a number of occasions to Gregory's position in fashionable Edinburgh society and his inheritance of privilege and position. Asking what qualities defined men like Gregory, he responded:

suavity of manners, a specious carriage, an agreeable person, a pleasing address, a facetious conversation, a thorough knowledge of the politics and courtliness of high life. A splendid establishment, a gaudy carriage, family connections, and the solicitation of friends, [these] are [the] chief distinctions in [the physician's] profession.

He then proceeded to contrast such affectations with the plain, earnest sensibility of socially inferior surgeons like himself, stating:

We hope, for the credit of bare unsophisticated nature, that the honest and feeling heart, the thinking head, and the steady hand! the open liberal hand, which drops its alms while it is assuaging pain! is not more frequent in the gilded chariot, than in the humble walks of life; where men drag along the burden of their duties. ${ }^{50}$

Within the context of turn-of-the-century Edinburgh, then, emotion and sympathy played a powerful political role in surgeon's claims to social and professional recognition in the face of opposition from establishment physicians like James Gregory. It should perhaps come as no surprise that it was Edinburgh that played host to one of the earliest articulations of this surgical ideal. As the erstwhile residence of David Hume and Adam Smith it was, after all, the spiritual and intellectual home of sensibility. ${ }^{51}$

Emotion and sympathy played a similarly political role in the movement for medical and surgical reform that characterised the 1820s, 1830s and 1840s. This chapter opened with a letter to The Lancet from 1824 and I suggested that there were many such reports of bungled operations reported in that journal in early decades of its existence. The author of this letter was clearly aware of the precedent that had already been established and opened by stating that:

As the principal object of the LANCET is to improve the medical and chirurgical practice, and, of course, to ameliorate the condition, and to diminish the distress of the subjects of its operation; you may not, perhaps, think the following observations unworthy of insertion. ${ }^{52}$

Perhaps the most famous of these cases involved the Guy's Hospital surgeon and nephew of Astley Cooper, Brandsby Cooper. In 1828, Cooper performed a lithotomy on a patient named Stephen Pollard. However, rather than the ten minutes that the operation should ideally have taken, Cooper actually took the best part of an hour. During that time Pollard, who later died, 
experienced excruciating pain and Cooper appeared flustered, apparently incapable of locating the stone, calling on his attendants for assistance and repeatedly explaining himself to the audience. Indeed, in many ways Cooper's operation was a textbook example of how not to conduct oneself under such circumstances and The Lancet was merciless in its coverage, publishing an excoriating account of the operation as a dramatic tragedy in three acts. As a result of this, Cooper took The Lancet's editor and founder, Thomas Wakley, to court for libel, a case which he won, albeit with significantly reduced damages. ${ }^{53}$

One of the most remarkable things about this case is the ways in which, during both the trial itself and in its coverage in The Lancet, Wakley presented the pain and suffering of Stephen Pollard as a function of Cooper's incompetence. Cooper, he alleged, was a perfectly pleasant and respectable gentleman but a manifestly imperfect surgeon who had attained his position at Guy's not through merit or hard work but through the nepotistic influence of his uncle. In defending his practice of publishing accounts of botched and incompetently performed operations, Wakley alleged that many of the arguments advanced against such reports 'consist, almost entirely of appeals to the passions, and pecuniary interests of the surgeon':

[A] young surgeon's professional prospects may be ruined, it is said, if his failures are blazoned forth to the public. All we have to say in answer to this objection is, that if a young man is elected to fill the office of surgeon to a public hospital, the public have a right to know in what manner he performs his duty.

He continued:

If it be taken as an appeal to our compassion, then we reply that there is a compassion due to patients as well as to surgeons, and that if the reputation or finances of the latter plead for suppression, the safety of the former calls imperiously for publicity.

Moreover, Wakley characterised the objections of what he called these 'Hole and Corner' surgeons as indicative of their callous indifference to the wellbeing of those under their care:

The suffering and destruction of the patient go for nothing, and it is only the mortification endured by the Surgeon, from the consciousness of his own ignorance which excites their sympathy and commiseration. ${ }^{54}$

As with John Bell, then, Wakley and the London-based radical medical reformers of the 1820s and 1830s harnessed the ideals of sympathy and compassion as part of a powerful political critique of the corporate elites. However, unlike in the case of turn of the century Edinburgh where it was established physicians who were the objects of scorn, Wakley's targets were what he called surgical 'Bats'. Many of those exposed in The Lancet's accounts 
were, like Cooper, identified as surgeons who owed their positions to patronage and influence rather than talent and ability. As such, the pain and suffering of the patients under their hands was not simply the result of individual incompetence, it was the inevitable product of a corrupt and tyrannical system predicated on nepotism and oligarchy. Only by thoroughgoing reform, it was alleged, reform which would place competent and compassionate surgeons in positions of public responsibility, could the sufferings of patients be alleviated and the safety of the public guaranteed. And it should come as no surprise if these competent and compassionate surgeons of the reforming imagination bore a remarkable resemblance to the marginal surgeon-apothecaries who comprised a significant proportion of The Lancet's most avid readership.

\section{Conclusion AND Legacy}

In this chapter I have endeavoured to demonstrate the ways in which an approach that takes the emotions seriously might nuance and complicate our understandings of the history of pre-anaesthetic surgery. In general, historians have tended to focus on the operations of surgical dispassion, or what we might now term clinical detachment. What this research suggests, however, is that compassion and emotional expression played a surprisingly important role in shaping the cultures of early nineteenth-century operative surgery as well as the identities of its practitioners. In the decades immediately preceding the advent of anaesthesia, pain became a central concern of surgical discourse and the response to this concern was shaped by the cultures of sentiment and sensibility. However, this culture of compassion was no 'natural' reaction to a self-evident problem. Rather, it was a culturally and historically contingent phenomenon which could be harnessed to the ideologies and ambitions of medical reform. In the hands of men like John Bell and Thomas Wakley, the image of the surgeon as a man of refined and honest sentiment was linked to a critique of the medical and surgical ancien regime, providing an idealised representation of a more expert, meritocratic and altruistic profession.

Needless to say, the advent of anaesthesia in the 1840s had a profound impact on surgery. The introduction of ether and chloroform was not simply a technical development; it served to reshape the social, political and emotional relations of the operating theatre. Though by no means straightforward or unproblematic, the use of chloroform effectively silenced the patient and, in the admittedly self-interested words of Frederick Treves, transformed the operating theatre 'from a shambles to a chamber of sleep' ${ }^{55}$ Surgeons could now take longer and, with the risk of shock significantly reduced, could reach far deeper into the body. In many ways, the surgical operation now resembled the anatomical dissections that were central to surgical education and acculturation. ${ }^{56}$ The extent to which this helped to reshape the emotional cultures of surgery is, however, as yet unclear. One might assume that, with the patient now less of an immediate concern, surgeons did not need to be quite as emotionally astute or 
attuned as they had been when the patient's temperament could have a material effect on the outcome of a procedure. One might also assume that, with the demise of a Romantic sensibility, and the rise of a more ruggedly masculine Victorian archetype, surgeons became less emotionally expressive. And yet evidence suggests that surgeons continued to describe their work in emotional terms. Treves, for example, in the same speech of 1900 stated that the surgeon had 'gained much in the direction of the sympathetic handling of the patient and in the culture of gentleness'. ${ }^{57}$

Indeed, even today, in an age of painless, sterile and increasingly minimally invasive surgery, surgeons remain unclear about the place of emotions in their work and their identity as emotional beings. In her work on modern surgical education in the USA, for example, Rachel Prentice relates how some of her surgical subjects struggled to adequately define their emotional relationship with patients, coming up with generally inadequate labels such as 'detached compassion' and 'compassionate objectivity'. In this case it was not clear either who or what was being protected by this apparent emotional distance. Was it rational, clinical judgement or the surgeons themselves, who might otherwise be emotionally contaminated by so much pain and suffering. ${ }^{58}$ These are questions that remain to be explored, but what is clear is that the emotions continue to play a powerful, if generally overlooked, role in the practise of surgery.

\section{Notes}

1. The Lancet, 2:42 (17 July 1824): 91-93.

2. Claire Tomalin, Samuel Pepys: The Unequalled Self (London: Viking, 2002), 63-65.

3. Sofia C. Zambrano, et al. 'How Do Surgeons Experience and Cope with the Death and Dying of Their Patients? A Qualitative Study in the Context of Life-limiting Illnesses', World Journal of Surgery 37 (2013): 935-944.

4. Henry Marsh, Do No Harm: Stories of Life, Death and Brain Surgery (London: Weidenfeld and Nicolson, 2014).

5. See also chapter 'Opening the Abdomen: The Expansion of Surgery', on abdominal surgery, by Sally Frampton and chapter 'Opening the Skull: Neurosurgery as a Case Study of Surgical Specialisation', on neurosurgery, by Delia Gavrus in this handbook.

6. Frances Burney, 'Journal Letter to Esther Burney, 22 March-June 1812', in Peter Sabor and Lars E. Trodie (eds), Frances Burney: Journals and Letters (Penguin: 2001), 433.

7. Ibid., 442 .

8. Ibid., 435; 440-441.

9. Ibid., 443 .

10. For example, see Frederick Treves, 'Address in Surgery: The Surgeon of the Nineteenth Century', The Lancet 156, vol. 2 (1900): 312-317. See also chapter 'Surgery and Its Histories: Purposes and Contexts', on histories of surgery, by Christopher Lawrence in this handbook. 
11. Lynda Payne, With Words and Knives: Learning Medical Dispassion in Early Modern England (Aldershot: Ashgate, 2007), 1.

12. Two Introductory Lectures delivered by Dr William Hunter, to his last course of Anatomical Lectures, at his theatre in Windmill-Street (London: J. Johnson, 1784), 67.

13. Quoted in Payne, With Words and Knives, 145.

14. Christopher Lawrence, 'Medical Minds, Surgical Bodies: Corporeality and the Doctors', in Christopher Lawrence and Steven Shapin (eds), Science Incarnate: Historical Embodiments of Natural Knowledge (Chicago: Chicago University Press, 1998), 194.

15. Peter Stanley, For Fear of Pain: British Surgery, 1790-1850 (Amsterdam: Rodopi, 2003), 189.

16. Ibid., 248-257.

17. Ibid., 61-81.

18. Martin S. Pernick, A Calculus of Suffering: Pain, Professionalism and Anaesthesia in Nineteenth-Century America (New York: Columbia University Press, 1985). See also chapter 'Surgery and Anaesthesia: Revolutions in Practice', on anaesthesia, by Stephanie Snow in this handbook.

19. Pernick, A Calculus of Suffering, 148-167; Stephanie J. Snow, Operations Without Pain: The Practice and Science of Anaesthesia in Victorian Britain (Basingstoke: Palgrave Macmillan, 2006); idem, Blessed Days of Anaesthesia: How Anaesthetics Changed the World (Oxford: Oxford University Press, 2008).

20. Joanna Bourke, The Story of Pain: From Prayer to Painkillers (Oxford: Oxford University Press, 2014), 231-269.

21. For a broad overview of this complex field, see Jan Plamper, The History of Emotions: An Introduction (Oxford: Oxford University Press, 2015); idem, 'The History of Emotions: An Interview with William Reddy, Barbara Rosenwein and Peter Stearns', History and Theory 49 (2010): 237-265.

22. Carol Z. Stearns and Peter N. Stearns, Anger: The Struggle for Emotional Control in America's History (Chicago: Chicago University Press, 1986).

23. Barbara H. Rosenwein, Emotional Communities in the Early Middle Ages (Ithaca, NY: Cornell University Press, 2006).

24. Barbara H. Rosenwein, 'Worrying About Emotions in History', American Historical Review 107 (2002): 821-45.

25. William M. Reddy, The Navigation of Feeling: A Framework for the History of Emotions (Cambridge: Cambridge University Press, 2001).

26. L. S. Jacyna, 'Images of John Hunter in the Nineteenth Century', History of Science 21 (1983): 85-108.

27. The Lancet, 2:48 (28 August 1824): 277.

28. Rachel Prentice, 'Drilling Surgeons: The Social Lessons of Embodied Surgical Learning', Science, Technology and Human Values 32 (2007): 535.

29. The Lancet, 1:1 (5 October, 1823), 4.

30. Frederic Skey, Operative Surgery (1850): 21.

31. Stanley, For Fear of Pain: 222-224.

32. The Lancet, 1:1 (5 October, 1823): 6.

33. The Lancet, 20:514 (6 July 1833): 454.

34. Thomas Schlich, "The Days of Brilliancy are Past": Skill, Styles and the Changing Rules of Surgical Performance, ca. 1820-1920', Medical History 59 (2015): 379-403. 
35. The Lancet, 20:514 (6 July 1833): 454. Emphasis added.

36. Skey, Operative Surgery, 21. Emphasis added.

37. Astley Cooper and Benjamin Travers, Surgical Essays, Part l (1818), 111-112.

38. There is a significant body of scholarship on the philosophy, history and culture of sympathy, sentiment and sensibility. Some notable examples include John Mullan, Sentiment and Sociability: The Language of Feeling in the Eighteenth Century (Oxford: Clarendon, 1988); G. J. Barker-Benfield, The Culture of Sensibility: Sex and Society in Eighteenth-Century Britain (Chicago: Chicago University Press, 1992); Paul Goring, The Rhetoric of Sensibility in EighteenthCentury Culture (Cambridge: Cambridge University Press, 2009); Michael L Frazer, The Enlightenment of Sympathy: Justice and the Moral Sentiments in the Eighteenth Century and Today (Oxford: Oxford University Press, 2010); Henry Martyn Lloyd (ed.), The Discourse of Sensibility: The Knowing Body in the Enlightenment (London: Springer, 2013).

39. The Lancet, 20:514 (6 July 1833): 453-459.

40. The Lancet, 20:514 (6 July 1833): 453-459.

41. The Lancet, 3:54 (9 October 1824): 23.

42. The Lancet, 1:16 (18 January 1824): 96.

43. The Lancet 1:19 (8 February 1824): 191.

44. Carin Berkowitz, Charles Bell and the Anatomy of Reform (Chicago: Chicago University Press, 2015).

45. John Bell, Answer for the Junior Members of the Royal College of Surgeons of Edinburgh to the Memorial of Dr James Gregory (Edinburgh: Peter Hill, 1800), 2.

46. Bell, Answer, 6-7.

47. Bell, Answer, 7.

48. For example, see Markman Ellis, The Politics of Sensibility: Race, Gender and Commerce in the Sentimental Novel (Cambridge: Cambridge University Press, 1996).

49. Maureen Harkin, 'Mackenzie's Man of Feeling: Embalming Sensibility', ELH 61:2 (1994), 317-340; Ildiko Csengei, "“I will not weep": Reading through the Tears of Henry Mackenzie's "Man of Feeling"', The Modern Language Review 103 (2008): 952-968.

50. Bell, Answer, 20-21.

51. Roger Emerson, Essays on David Hume, Medical Men and the Scottish Enlightenment (Aldershot: Ashgate, 2009); James Buchan, Capital of the Mind: How Edinburgh Changed the World (London: John Murray, 2003).

52. The Lancet, 2:42 (17 July 1824): 91.

53. For a detailed analysis of the case, see Michael Brown, "Bats, Rats and Barristers": The Lancet, Libel and the Radical Stylistics of Early Nineteenth Century English Medicine, Social History 39 (2014): 182-209.

54. The Lancet, 2:39 (26 June 1824): 397.

55. Treves, 'Address in Surgery', 314.

56. On the importance of anatomy to surgical identity, see Michael Sappol, $A$ Traffic of Dead Bodies: Anatomy and Embodied Social Identity in NineteenthCentury America (Princeton: Princeton University Press, 2002), 74-98; John Harley Warner and John M. Edmonson, Dissection: Photographs of a Rite of Passage in American Medicine, 1880-1930 (New York: Blast Books, 2009).

57. Treves, 'Address in Surgery', 314.

58. Rachel Prentice, Bodies in Formation: An Ethnography of Anatomy and Surgical Education (Durham, NC: Duke University Press, 2012), 127-131. 


\section{FURTHER READING}

Barbara H. Rosenwein, 'Worrying About Emotions in History', American Historical Review 107 (2002): 821-845.

G. J. Barker-Benfield, The Culture of Sensibility: Sex and Society in Eighteenth-Century Britain (Chicago: Chicago University Press, 1992).

Joanna Bourke, The Story of Pain: From Prayer to Painkillers (Oxford: Oxford University Press, 2014).

Lynda Payne, With Words and Knives: Learning Medical Dispassion in Early Modern England (Aldershot: Ashgate, 2007).

Martin S. Pernick, A Calculus of Suffering: Pain, Professionalism and Anaesthesia in Nineteenth-Century America (New York: Columbia University Press, 1985).

Michael Brown, "Bats, Rats and Barristers": The Lancet, libel and the radical stylistics of early nineteenth-century English medicine' Social History 39 (2014): 182-209.

Peter Stanley, For Fear of Pain: British Surgery, 1790-1850 (Amsterdam: Rodopi, 2003).

Rachel Prentice, Bodies in Formation: An Ethnography of Anatomy and Surgical Education (Durham, NC: Duke University Press, 2012).

Thomas Schlich, "“The Days of Brilliancy are Past": Skill, Styles and the Changing Rules of Surgical Performance, ca. 1820-1920', Medical History 59 (2015): 379-403.

William M. Reddy, The Navigation of Feeling: A Framework for the History of Emotions (Cambridge: Cambridge University Press, 2001). 
Open Access This chapter is licensed under the terms of the Creative Commons Attribution 4.0 International License (http://creativecommons.org/licenses/ by $/ 4.0 /)$, which permits use, sharing, adaptation, distribution and reproduction in any medium or format, as long as you give appropriate credit to the original author(s) and the source, provide a link to the Creative Commons license and indicate if changes were made.

The images or other third party material in this chapter are included in the chapter's Creative Commons license, unless indicated otherwise in a credit line to the material. If material is not included in the chapter's Creative Commons license and your intended use is not permitted by statutory regulation or exceeds the permitted use, you will need to obtain permission directly from the copyright holder.

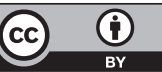

